\title{
UNAPREĐENJE SISTEMA MENADŽMENTA KVALITETOM U PREDUZEĆU „PIP NOVI SAD“
}

\section{IMPROVEMENT OF QUALITY MANAGEMENT SYSTEM IN „PIP NOVI SAD” ENTERPRISE}

Srđan Jekić, Fakultet tehničkih nauka Novi Sad

\section{Oblast - INŽENJERSKI MENADŽMENT}

Kratak sadržaj - U ovom radu je prikazan značaj kvaliteta na poslovanje jednog preduzeća, i njegova uloga u uspešnosti poslovanja. Navedeni su standardi koje preduzeće „PIP“ primenjuje, i koje sve procedure se sprovode. Predstavljen je alat za samoocenjivanje iz standarda ISO 9004, pomoću kog je izvršseno samoocenjivanje perfomansi organizacije. Na osnovu dobijenih rezultata, predložene su mere unapređenja kako bi se podigao nivo zrelosti organizacije.
\end{abstract}

Ključne reči: ISO, Model izvrsnosti, Samoocenjivanje

Abstract - This paper presents the importance of quality on the company's business and its role in business success. The standards that the company "PIP" applies are listed along with the procedures which are carried out. A tool for self-assessment from the ISO 9004 standard was presented, which defined self-assessment of the organization's perfomance. Based on the obtained results, improvement measures are proposed in order to raise the level of the organizational success.

Keywords: ISO, TQM, Self-Assessment

\section{Uvod}

Cilj ovog rada je unapređenje sistema menadžmenta kvalitetom u preduzeću „PIP Novi Sad“. To se postiže uz pomoć alata za samoocenjivanje koje obezbeđuje stepen zrelosti sistema menadžmenta i ukupan pogled na perfomanse organizacije. Ovaj alat može biti od pomoći i kod identifikovanja oblasti za inovacije i/ili poboljšavanja za određivanje prioriteta za naknadne mere [1].

Svako preduzeće koje prodaje određen proizvod ili pruža određenu uslugu mora da vodi računa o kvalitetu svojih proizvoda/usluga kako bi zadovoljili zahteve svojih kupaca/korisnika. Pored kvaliteta svaka organizacija treba da nastoji da poboljšava svoje poslovanje na veči nivo bez obzira o kom brendu se radilo.PIP poseduje četiri glavne procedure: procedure analitike i unapređenja prodaje, interne provere, preispitivanja IMS-a i određivanje korektivnih i preventivnih mera [2].

\subsection{Osnovni podaci o preduzeću}

Preduzeće "PIP Novi Sad" sa sedištem u Čeneju proizvodi smeše i poboljšivače za pekarske proizvode. Poseduju nekoliko distributivnih centara odakle

\footnotetext{
NAPOMENA:

Ovaj rad proizašao je iz master rada čiji mentor je bio dr Milan Delić vanr. prof.
}

otpremaju svoje proizvode do ugovorenih kupaca, uglavnom pekara ili restorana. Preduzeće je osnovano 19.08.1992. sa tačno definisanom vizijom - prepoznatljiv brend i ravnopravno članstvo među najznačajnijim preduzećima $\mathrm{u}$ oblasti pekarske industrije $\mathrm{u}$ regionu sa snažnom stručnom osnovom, savremenim tehničkotehnološkim rešenjima sa kapacitetima koji odgovaraju potrebama tržišta, kao i kapacitetima koji ostvaruju sopstvene ideje i rešenja.

Preduzeće proizvodi pekarske smeše i poboljšivače od kojih se dobijaju sledeći proizvodi: pekarski proizvodi, produžena svežina, beskvasni program, posno, krofne i lisnato testo [2].

\section{Kvalitet}

Kvalitet je mera (nivo) zadovoljenja zahteva i očekivanja zainteresovanih strana. Kako bi se na najlakši način opisao kvaliteta, dat je primer sa lenjirom, gde su na zamišljenom lenjiru označene kategorije: ispunjen, neispunjen ili prevaziđen zahtev ili očekivanja zainteresovanih strana. Na kraju se taj lenjir upoređuje sa proizvodima/uslugama kako bi se izmerio njihov kvalitet.

Kvalitet nekog proizvoda ili usluge predstavlja individualnu stvar, i ako neko kaže da ima proizvod odličnog kvaliteta to verovatno znači da su izvršena ispitivanja zainteresovanih strana o kvalitetu tog proizvoda ili usluge i da su se oni izjasnili na skali koja određuje kvalitet [3].

\subsection{TQM}

TQM (Total quality management) je koncept definisan 80-tih godina prošlog veka i predstavlja Američku i Japansku strategiju za unapređenje kvaliteta poslovanja. U Japan su 50-tih godina dolazili Američki stručnjaci sa ciljem da tehnički edukuju Japanske stručnjake kako bi na što bolji način upravljali svojim preduzećima.

Rad Edvarda Deminga se posebno ističe, on je u to vreme održavao seminare o kontroli kvaliteta širom Japana. Japanski menadžeri su teoretska dostignuća svojih kolega iz Amerike primenili u praksi i rezultati su bili fenomenalni. Postignuta je povećanost produktivnosti smanjenjem odstupanja, grešaka i rasipanja poslovnih resursa. Ovaj način unapređivanja produktivnosti se označava terminom "lančana reakcija" gde se unapređuje kvalitet, troškovi smanjuju i produktivnost se povećava, što utiče na samo tržište, jer preduzeće može po niskoj ceni da ponudi kvalitetan proizvod i obezbedi opstanak $u$ poslovanju. 
Ovaj koncept je u mnogome doprineo poboljšanju stanja Japanske privrede, gde je borba za unapređivanje produktivnosti dovela do razvoja privrede u Japanu i probijanju Japanskih preduzeća na međunarodno tržište [4].

\section{ORGANIZACIJA ZA STANDARDIZACIJU ISO}

Važnost standarda je veoma velika u svim aspektima naših života. Standardi osiguravaju željene karakteristike koje proizvodi i usluge treba da poseduju po pitanju kvaliteta, sigurnosti, efikasnosti, pouzdanosti, ekonomske cene, zamenljivosti i odnosa prema okolini. Kada se proizvodi i usluge susretnu sa našim očekivanjima, zadovoljenje naših standarda se prihvata kao normalnost. Međutim, kada nema standarda mogu se očekivati problemi i loš kvalitet, opasnost prilikom korišćenja i nemogućnosti uklapanja i korišćenja sa drugom opremom. Kada proizvodi, uređaji, mašine i sistemi rade dobro i sigurno, to je zato što su u saglasnosti sa standardima. Organizacija koja je zadužena sa propisivanje hiljade standarda koje važe svuda u svetu i koja je odgovorna da bi se takvo stanje održavalo je ISO. ISO standardi obezbeđuju sociološke, tehnološke i ekonomske benifite [4].

\subsection{ISO 9001}

ISO 9001 je međunarodni standard koji sadrži zahteve za sistem upravljanja kvalitetom koje organizacija mora ispuniti da bi uskladila svoje poslovanje sa međunarodnim normama. Sistem kvaliteta je upravljački sistem koji dovodi do ostvarenja postavljenih ciljeva $u$ smislu kvaliteta poslovanja i pružanja usluga. Ovaj sistem čine odgovornost subjekata $u$ organizaciji, organizaciona struktura, resursi i procesi koji su neophodni za upravljanje sistemom. ISO 9001 serije standarda se sastoji od:

ISO 9000 - Osnove i rečnik: predstavlja koncept sistema upravljanja kao i terminologiju koja se koristi

ISO 9001 - Zahtevi: kriterijumi koji se moraju ispunjavati ukoliko organizacija želi da dobije sertifikat i želi da radi u skladu sa standardima.

ISO 9004 - Smernice za poboljšanje perfomansi: na osnovu osam principa menadžmenta kvalitetom one se koriste od strane višeg menadžmenta kao okvir za usmeravanje organizacije, uz zadovoljenje potreba svih zainteresovanih strana a ne samo klijenata [5].

\subsection{ISO 9004}

ISO 9004 je model samoocenjivanja koji daje jednostavan pristup, lak za korišćenje, koji organizacije koriste kako bi odredile stepen zrelosti sistema menadžmenta kvalitetom i kako bi identifikovale u kojim je sve oblastima moguće sprovesti poboljšanja. ISO 9004 pruža smernice za unapređenje sposobnosti organizacije za dostizanje trajnog uspeha, i te smernice su zasnovane na činjenicama o tome gde treba investirati resurse za poboljšanja [5].

\section{ANALIZA STANJA SISTEMA MENADŽMENTA} KVALITETOM U PREDUZEĆU "PIP NOVI SAD”

1. 5.2 Relevantne zainteresovane strane: ustanovljeni su procesi za zadovoljenje potreba zainteresovanih strana. Ispituje se tržište, vrši se anketiranje kupaca kako bi njihove potrebe bile zadovoljene. Nivo zrelosti: 4.1

2. 5.3 Eksterna i interna pitanja: identifikovana su interna i eksterna pitanja i postoji analiza rizika i tačan mehanizam po kojem se to utvrđuje. Iz toga proizilaze određene mere unapređenja. Nivo zrelosti: 4.3

3. 6.2 Misija, vizija, vrednosti i kultura organizacije: misija i vizija su dobro definisani od strane rukovodstva. Neguju se vrednosti organizacije, gde je ključan segment kvalitet proizvoda, tako da je razumevanje uspostavljeno od svih zaposlenih. Nivo zrelosti: $\mathbf{4 . 3}$

4. 7.1 Liderstvo - opšte: postoje timovi za internu proveru, marketing, razvoj. Oni su multidisciplinarni timovi i koriste se za uspostavljanje i održavanje uspeha organizacije. U organizaciji ne postoji ni jedan proces ni rukovodilac procesa koji prvo ne konsultuje svoje zaposlene $u$ vezi sa dešavanjima. U slučaju bilo koje promene obaveštavaju se određeni rukovodioci $u$ zavisnosti u kom se sektoru desile promene. Nivo zrelosti: 5

5. 7.2 Politika i strategija: po poslovniku, kodeksima ponašanja, jasno defnisanim procesima, definisanim sistemom vrednosti utvrđene su potrebe zainteresovanih strana. Postoji procedura upravljanja i ophođenja prema imovini firme. Nivo zrelosti: $\mathbf{5 . 2}$

6. 7.3 Ciljevi: ciljevi su merljivi i jasno razumljivi preko plana poslovanja. Postoje kratkoročni godišnji ciljevi i dugoročni ciljevi na petogodišnjem nivou za određene segmente poslovanja Kratkoročni ciljevi se preispituju i stalno porede $\mathrm{u}$ toku godine sa prethodnim godinama. Ciljevi su definisani i nalaze se u poslovniku kvaliteta i stalno se osvežavaju i ažuriraju.. Nivo zrelosti: 3.3

7. 7.4 Komunikacija: komunikacija je definisana prema procesima za određivanje stepena komunikacije. Nivo zrelosti: 2 .

8. 8.1 Menadžment procesima - opšte: postupci su uspostavljeni u šemi međusobnih veza procesa, i integrisani su sa politikom, strategijom i ciljevima organizacije. Nivo zrelosti: 4.1

9. 8.2 Definisanje procesa: definisani su ključni procesi: nabavka, proizvodnja i prodaja i pomoćni: transport, projekt menadžment, služba opštih pravnih poslova. Ovi procesi se odnose na zadovoljenje potreba zainteresovanih strana i realizaciju proizvoda. Nivo zrelosti: 2.2

10. 8.3 Odgovornost i ovlašćenja za procese: definisana su u procedurama, u sistematizaciji radnih mesta, poslovniku kvaliteta, radnim ugovorima. Svaka procedura sadrži ko to prati, koliko često, i šta u slučaju ako ne dođe do slaganja tj. mere u slučaju odstupanja. Nivo zrelosti: 4.3

11. 8.4 Upravljanje procesima (upravljanje usklađenosti/ povezivanjem procesa): organizacija sprovodi analize $u$ slučaju odstupanja, gde se pravi izveštaj sa planom kontrole, prodaje i marketinga kao jednim primerom. Izveštaj sadrži ključne tačke gde se navode korisnici jer se prodaja njima bavi, parametri su kontaktirani korisnici, broj kontaktiranih i postojećih korisnika. Izveštaj prati analitičar prodaje, i na kraju meseca se formira nalaz, sa grafikonima gde se u ekselu tačno vidi da li postoji nekih odstupanja i na osnovu toga se predlažu mere. Nivo zrelosti: $\mathbf{4 . 2}$

12. 8.4 Upravljanje procesima (postizanje višeg nivoa performansi): cillj je da se dostiže uvek jedan viši nivo, zato služe planovi kontrole gde se preko njih analiziraju 
ključni problemi u procesima ne bi li se ti procesi stalno unapređivali. Nivo zrelosti: $\mathbf{3 . 1}$

13. 8.4 Upravljanje procesima (održavanje postignutog nivoa): na svim procesima (i pomoćnim i glavnim) su definisani parametri. Svaki parameter ima graničnu vrednost i ako ona ode ispod ili iznad odgovarajuće brojke definisane su mere koje to rešavaju. Nivo zrelosti: 4.4

14. 9.1 Upravljanje resursima - opšte: resursi se upravljaju u skladu sa ciljevima organizacijeri postizanju efektivnosti i efikasnosti organizacije kako bi se ostvario uspeh. Organizacija kad kupuje određenu opremu zahteva od dobavljača sve dobre perfomanse i karakteristike $u$ pogledu opreme, sirovina standarda koje moraju da imaju. Moraju da rade analize sirovina što isto traže i kupci od PIP a gde se stvara uzročno posledična veza i međusobna povezanost. Nivo zrelosti: $\mathbf{4 . 4}$

15. 9.2 Ljudi: ljudi predstavljaju najvažniji resurs. Često se pravi presek u pogledu potreba ljudskih resursa, da li u određenim segmentima poslovanja postoji višak ili manjak ljudskog kadra. Zaposleni su svesni svojih mogučnosti i kako na najbolji način mogu doprineti unapređenju poslovanja. Nivo zrelosti: 4.3

16. 9.3 Organizaciono znanje: organizacija ima plan obuke, postoje preispitivanja, sastanci, kolegijumi gde se prenose znanje na nove ljude $u$ organizaciji. Postoje utvrđeni načini kako se dolazi do stručnog kadra, koji prolaze obuku kroz date procese. Nivo zrelosti: 2

17. 9.4 Tehnologija: u demo centru se vrši analiza i preispitivanje tehnologije. Oprema i mašine se posmatraju i upoređuju sa postojećom tehnologijom.. Sva tehnologija i oprema je najnovija, ali kako tehnologija brzo napreduje tako postoje stalna ažuriranja, odnosno njeno obnavljanje po potrebi. Nivo zrelosti: $\mathbf{5 . 2}$

18. 9.5 Infrastruktura i radna sredina: uspostavljeni su procesi primene i unapređenja infrastrukture $\mathrm{i}$ radne sredine. Ceo kompleks u Čeneju poseduje dobru infrastrukturu od puteva, osvetljenja do sopstvene fabrike vode. Nivo zrelosti: 3

19. 9.6 Eksterno nabavljeni resursi: eksterno nabavljeni resursi nisu predmet posmatranja. Nivo zrelosti: 1

20. 9.7 Prirodni resursi: od prirodnih resursa organizacija ima svoju fabriku vode koja im služi samo za piće, jer se ne koristi u proizvodnji. Postoje ugovori sa firmama koja se bavi upravljanjem otpada, koja dolazi i odnosi otpad, ali organizacija ne upravlja prirodnim resursima. Nivo zrelosti: 1

21. 10.1 Analiza i vrednovanje performansi organizacije opšte: analiziraju se ciljevi, planovi poslovanja, donesene mere za unapređenje i njihova realizacija koje doprinose dobrom strateškom odlučivanju. Ključni indikatori perfomansi (KPI) su uspostavljeni i preispituju se u skladu sa politikom preduzeća. Nivo zrelosti: 3

22. 10.2 indikatori performansi: Ključni indikatori perfomansi su uspostavljeni i to su: prodaja, proizvodi nabavka. Prilikom odabira ključnih perfomansi uzimaju se u obzir potrebe i očekivanja zainteresovanih strana. Nivo zrelosti: 3.2

23. 10.3 Analiza performansi: koriste se osnovni statistički alati za analizu perfomansi, a perfomanse se analiziraju putem preispitivanja, kolegijuma, analize ciljeva, i analize rizika. Nivo zrelosti: $\mathbf{2 . 2}$

24. 10.4 Ocena performansi: perfomanse se ocenjuju na osnovu potreba zainteresovanih strana, gde organizacija kroz razne ankete, proveravanja, mere nivo zadovoljstva zainteresovanih strana i na osnovu toga ocenjuju perfomanse. Nivo zrelosti: $\mathbf{3 . 2}$

25. 10.5 Interne provere: interne provere se vrše jednom godišnje, gde postoji tim za internu proveru. Proveravanje sistema donosi poboljšanje u poslovanju gde su usko povezane mere poboljšanja i ciljevi. Tačno su definisani mehanizmi po kojima se sprovode interne provere tako da se do grešaka teško dolazi, pošto je dobro utvrđeno kako se one sprovode. Nivo zrelosti: 3.2

26. 10.6 Samoocenjivanje: samoocenjivanje se ne sprovodi. Nivo zrelosti: 1

27. 10.7 Preispitivanje: preispitivanje se vrši jednom godišnje na kolegijumima. Preispituje se nivo kvaliteta $u$ odnosu na očekivanja korisnika, procesi rada koji nisu definisani, analiza rizika, uzroci pojave neusaglašenosti, ostvarenost mera i potrebe za korektivnim i preventivnim merama. Na osnovu toga se donose ključne odluke o daljem poslovanju. Nivo zrelosti: 3.3

28. 11.1 Poboljšanje, učenje iinovacije - opšte: sve se postiže na kolegijumima, kroz plan obuke, plan investicije. Poboljšanja se dostižu kroz korektivne i preventivne mere. Nivo zrelosti: 3

29. 11.2 Poboljšanje: poboljšanja se sprovode putem korektivnih i preventivnih mera koji su definisani procedurom, gde su tačno ustanovljene šeme i aktivnosti koje se sprovode kako bi došlo do napretka u poslovanju. Nivo zrelosti: 3.2

30. 11.3 Učenje: plan obuke se sprovodi na godišnjem nivou gde postoje interne i eksterne obuke. Eksterne obuke se održavaju za rukovodioce na raznim sektorima, gde organizacija angažuje stručne ljude u cilju unapređenja poslovanja i dostizanja većih ciljeva. Nivo zrelosti: $\mathbf{5 . 3}$

31. 11.4 Inovacije: organizacija u razgovoru sa dobavljačima kupcima analizira tržišta, i gde se na osnovu potreba zainteresovanih strana inovacije zasnivaju. Odlaskom na sajmove i kroz plan investicija ustanovljava koje su njene potrebe za inovacijama gde projekt menadžment donosi odluku o sudbini isith. Nivo zrelosti: 2

\section{MERE UNAPREĐENJA}

17.4 Komunikacija: uspostaviti komunikaciju u oba smera gde bi ljudi sa nižih pozicija (proizvodnja, komercijalni poslovi) iznosili svoja mišljenja na kolegijumima, sastancima sa menadžerima i time javno iznosili svoja razmišljanja i ono što im smeta. Time bi maker na indirektan način došlo do unapređenja poslovanja, jer bi menadžeri imali više predloga i mišljenja svojih kolega iz proizvodnje. i mehanizam povratnih informacija bi se uspostavio. Nivo zrelosti pre/posle poboljšanja: $2 / 3.3$.

2. 8.2 Definisanje procesa: u cilju boljeg definisanja svih procesa (pomoćnih i glavnih) treba napraviti kartu procesa za svaki pojedinačni proces, gde će organizacija imati bolji uvid u svaki proces i gde će njihovi sadržaji bili jasniji i precizniji. Time bi se procesi defnisali tako da 
se odnose i na obezbeđenje resursa i na menadžerske aktivnosti.

\section{Nivo zrelosti pre/posle poboljšanja: 2.2/3.1.}

3. 9.3 Organizaciono znanje: podići organizaciono znanje na jedan viši nivo razvijanjem strategije za upravljanjem informacijama i znanjem, kao podrška strategiji i politici organizacije. Strategija bi podrazumevala uspostavljenje procesa za identifikaciju važnih informacija i distribuciju takvih informacija. Nivo zrelosti pre/posle poboljšanja: 2/3.2.

4. 10.3 Analiza perfomansi: analizirati perfomanse organizacije iz više različitih uglova uz pomoć SWOT analize. SWOT analiza bi sagledala interne snage $i$ slabosti i eksterne šanse i pretnje koje mogu da se dogode. I time bi se identifikovali svi procesi, nedovoljni resursi, i utvrdilo novo organizaciono znanje. Nivo zrelosti pre/posle poboljšanja: 2.2/4.1.

5. 10.6 Samoocenjivanje: sprovesti samoocenjivanje gde bi organizacija sopstvenim ocenjivanjem odredila svoju zrelost i uvidela u kojim segmentima poslovanja je potrebno poboljšanje što bi dovelo do boljeg ukupnog učinka. Nivo zrelosti pre/posle poboljšanja: 1/3.

6. 11.4 Inovacije: ono što bi PIP mogao da inovira su procesi, odnosno procese inovacija za nove proizvode ili usluge. PIP proizvodi smeše za pekarske proizvode i prodaje svoje proizvode pekarama i restoranima, ali kada bi otvorili svoje sopstvene pogone gde bi prodavali gotove proizvode, organizacija bi stvorila jedan novi segment i podigla poslovanje na veći nivo. Nivo zrelosti pre/posle poboljšanja: $2 / 3.3$.

\subsection{Polarni dijagram}

Prikaz polarnog dijagrama nakon mera unapređenja, gde plava linija označava vrednosti kriterijuma pre unapređenja, a crvena linija vrednosti kriterijuma posle mera unapređenja.

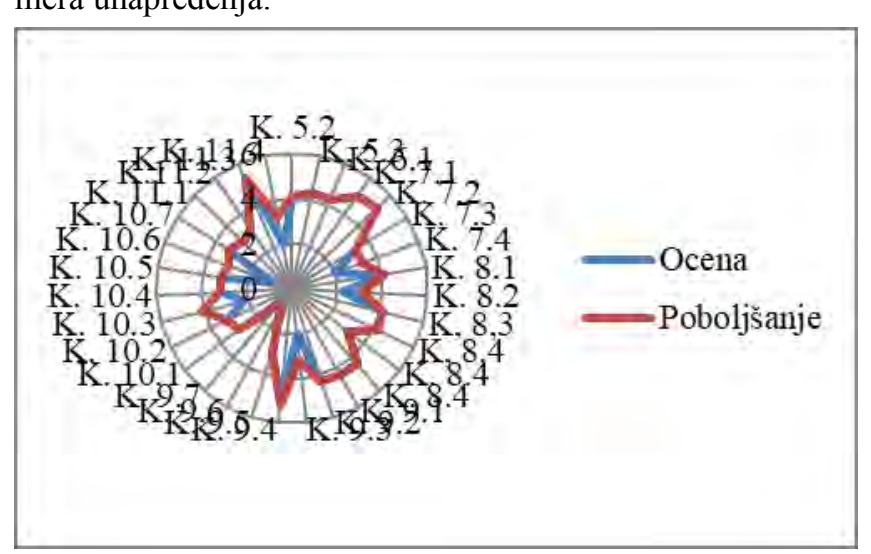

Slika 1. Polarni dijagram

\section{ZAKLJUČAK}

U radu je izvršeno samoocenjivanje preduzeća "PIP Novi Sad" po modelu samoocenjivanja sistema menadžmenta kvalitetom iz standarda ISO 9004:2018. S obzirom na delatnost organizacije, kvalitet predstavlja jedan od najznačajnijih segmenata poslovanja, gde organizacija ništa ne sme da prepusti slučaju i mora da uloži mnoge resurse ne bi li kvalitet proizvoda bio na visokom nivou a samim tim i očekivanja zainteresovanih strana (u ovom slučaju kupaca) uvek bila ispunjena.

Navedeni su standardi koje je preduzeće implementiralo u cilju lakšeg izvršenja poslovanja i podizanja ukupnog učinka. Prema alatu za samoocenjivanje definisano je 31 kriterijum. Nakon sagledavanja svih kriterijuma organizacije i njihovog ocenjivanja dati su predlozi unapređenja za šest kriterijuma, a oni su: komunikacija, definisanje procesa, organizaciono znanje, analiza perfomansi, samoocenjivanje i inovacije.

\section{LITERATURA}

[1] Alat za samoocenjivanje, (prevod obezbedio istraživački i tehnološki centar) Novi Sad septembar 2018. godine.

[2] https://www.pip-ns.com/ (preuzeto 01.10.2020.)

[3] https://mladilideri.rs/sta-je-kvalitet/(preuzeto 30.08.2020.)

[4] Upravljanje kvalitetom, Mr Siniša Papić, Beograd 2011. godine.

[5] https://www.eurostandard.rs/iso-9001-sistemmenadzmenta-kvalitetom/ (preuzeto 01.10.2020)

[6] Istraživački i tehnološki centar, Sistem menadžmenta kvalitetom, dr Vojislav Vulanović, dr Dragutin Stanivuković, dr Bato Kamberović, dr Rado Maksimović, dr Nikola Radaković, dr Vladan Radlovački, dr Miodrag Šilobad. Dr Ivan Beker, dr Dragoljub Šević, dr Slobodan Morača, Mr Srđan Vulanović, M.Sc. Stevan Milisavljević, Igor Kesić, M.Sc. Milan Delić, M.Sc. Nebojša Brkljač. Novi Sad, 2012. godine.

\section{Kratka biografija:}

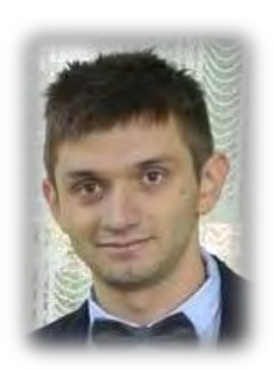

Srđan Jekić rođen je u Novom Sadu 1992. godine. Diplomirao na Fakultetu tehničkih nauka u Novom Sadu smer:Inženjerski menadžment.

kontakt: jekicsrdjan7@yahoo.com 